\title{
Carbohydrate metabolism and physiology of the parasitic protist Trichomonas vaginalis studied in chemostats
}

\author{
Benno H. ter Kuile \\ Tel: +1 212 3278144. Fax: +1212 3277974. e-mail: terkuil@ rockvax.rockefeller.edu
}

The Rockefeller University, 1230 York Avenue, New York, NY 10021, USA

\begin{abstract}
The parasitic protist Trichomonas vaginalis was cultured in chemostats with glucose or maltose as carbon and energy source. The maximum growth rate was about six divisions per day independent of the substrate, and the apparent $K_{m}$ for glucose was $\mathbf{0 . 3 7 5} \mathrm{mM}$. While growing on maltose, the growth rate depended linearly on the maltose concentration, indicating that in contrast to glucose metabolism a diffusion step is rate-limiting to maltose metabolism. Cultures were examined over a wide range of growth rates under four conditions: utilizing glucose or maltose as carbon and energy source, with the carbon source rate-limiting or present in excess. Cell density, cellular protein and carbohydrate content as well as residual substrate concentration in the culture fluid were measured at each steady state. The protein content was constant at $100 \mathrm{pg}$ protein per cell except when $T$. vaginalis was cultured under glucose limitation; in the latter case, slow-growing cells had less protein than cells grown at high rates. When growing under glucose limitation $T$. vaginalis metabolism changed to become more energy efficient at growth rates exceeding about half the maximum rate. The maintenance energy at the low growth rates accounted for approximately half of the total carbon consumption, which is high in comparison to other micro-organisms. At low growth rates the yield on maltose exceeded that on glucose, when expressed in terms of carbon equivalents. The yields on maltose and glucose were equal, but much lower, when the carbon source was not rate-limiting. A comparison of the data of this study with similar studies on other organisms suggests that the high maintenance energy of $\boldsymbol{T}$. vaginalis may be used primarily for maintaining homeostasis of the internal conditions to enable growth and survival in the vagina.
\end{abstract}

Keywords: Trichomonas vaginalis, energy metabolism, chemostats, carbohydrate metabolism

\section{INTRODUCTION}

The carbohydrate metabolism of the anaerobic flagellated protist Trichomonas vaginalis, a parasite of the human urogenital tract, has been explored in considerable detail (Müller, 1988, 1991). Mitochondria are absent in this organism and part of its pathway for carbohydrate metabolism is located in hydrogenosomes (Müller, 1993). Glucose, maltose and glycogen can be utilized as carbon and energy sources (Read, 1957; Simonetti et al., 1989). Glucose is transported across the plasma membrane by a facilitated diffusion carrier (Ter Kuile \& Müller, 1993). Maltose is hydrolysed in the stagnant layer around the cell by an extracellular $\alpha$-glucosidase and subsequently taken up in the form of glucose (Ter Kuile \& Müller, 1994). The energy metabolism of cultured cells is fermentative with glycerol, lactate, acetate and $\mathrm{CO}_{2}$ as end-products, both in the presence and in the absence of oxygen (Mack \& Müller, 1980). Under anaerobic conditions $\mathrm{H}_{2}$ is produced, an unusual product for a eukaryote. Traces of oxygen stimulate growth and the partial oxygen pressure influences the relative abundance of metabolic end-products formed (Lloyd \& Paget, 1991).

Studies on the energy metabolism of this organism have been conducted in cultures and with cultured cells. In contrast, there is an almost complete ignorance of its physiology in the human vagina, its primary habitat. This 
immediate environment of the organism undergoes extensive changes during the menstrual cycle and also shows a broad spectrum of differences depending on the extent of infection. In subclinical infections vaginal conditions are normal, including low $\mathrm{pH}$, while in florid acure trichomoniasis there is abundant discharge and elevated pH (Müller, 1988; Fouts \& Kraus, 1980). Obviously, T. vaginalis copes with the significant changes that occur in its environment, but by as yet unknown mechanisms. The varying abundance of the parasite and the possibility of its asymptomatic persistence in the vagina indicate that its multiplication rate can vary within a wide range. Because direct studies of the in situ physiology of $T$. vaginalis are well-nigh impossible, a detailed understanding of its physiological adaptability and the definition of its tolerance of environmental changes is desirable.

Chemostats allow the growth of cultures under condition: that reflect natural conditions more closely than batch cultures (Veldkamp, 1976). Due to the continuous replacement of part of the culture with fresh medium, chemostat cultures do not reach a stationary phase, but the cells continue to multiply at the pace allowed by the supply of fresh nutrients. After three to five volume changes, a so called steady-state is reached. At steady-state the increase of the biomass as a fraction of the existing biomass, the specific growth rate $(\mu)$, is controlled by the concentration of one growth-rate-limiting component of the medium and equals the dilution rate $(D)$. The possibility of growing organisms at constant conditions and growth rates, according to experimental design, for prolonged periods of time, enables a far more detailed study of their physiology than is possible in batch cultures. A number of important physiological parameters, such as maintenance energy and yield, can only be measured in chemostats. Changes in the nature of the growth-ratelimiting substrate, either the carbon and energy source or another essential component, greatly affect the metabolism of most organisms studied so far (Veldkamp, 1976; Stouthamer, 1979).

The chemostat is widely used in the study of prokaryotic micro-organisms but in spite of its potential has been used only infrequently with eukaryotic organisms other than yeasts. A particularly promising application of chemostats is in the study of those parasitic protists which lead an extracellular life in their host, i.e. obtain all their nutrients in the form of dissolved molecules. This approach has been applied successfully to study the physiology of the parasitic protists Trypanosoma brucei and Leishmania donovani, but only in one study on $T$. vaginalis. In the chemostat $T$. vaginalis can be grown at both high and very low growth rates, corresponding to doubling times from $4 \mathrm{~h}$ down to $100 \mathrm{~h}$ (Lehker \& Alderete, 1990). Changes in the $\mathrm{pH}$ of the medium severely affect the acid production, indicating shifts in metabolism (Lehker \& Alderete, 1990).

The present study was undertaken to explore the energy metabolism of $T$. vaginalis with glucose and maltose as carbon and energy sources. The results show a great adaptability of the organism and a very high maintenance energy. The outcome of the present study suggests that the metabolic strategy of $T$. vaginalis is to devote considerable resources to maintaining internal homeostasis, corresponding to the requirements for survival in an environment where nutrient supplies and other conditions vary widely. The mechanisms for adaptation of the carbohydrate metabolism are explored in the accompanying paper (Ter Kuile, 1994).

\section{METHODS}

Culture conditions. Trichomonas vaginalis (strain NIH-C1, ATCC 30001) was grown in single-stage, flow-controlled chemostats with a working volume of 100 or $200 \mathrm{ml}$, whose design has been described earlier (Ter Kuile \& Opperdoes, 1991). The $\mathrm{pH}$ was maintained at $6.40 \pm 0.02$ with a control unit (New Brunswick $\mathrm{pH} 4000$ ) pumping $1 \mathrm{M} \mathrm{NaOH}$. The driving gas was $99 \cdot 99 \%$ pure nitrogen to maintain anaerobic conditions. Any oxygen in the $0.01 \%$ impurities was removed rapidly because $T$. vaginalis is microaerophilic. The culture temperature was $37^{\circ} \mathrm{C}$. Chemostats were autoclaved at $120^{\circ} \mathrm{C}$ for $20 \mathrm{~min}$. The $\mathrm{pH}$ electrodes (Orion g11500 combination electrode) were sterilized separately by overnight exposure to the vapours of an ethanol/formalin $(1: 1, v / v)$ mixture.

Phosphate-buffered tryptone/yeast extract medium (Diamond, 1957) was prepared without added carbohydrate, heat-sterilized and supplemented with horse serum after cooling. Glucose or maltose was used as carbon and energy source. Glucose was filter-sterilized, but maltose was added before autoclaving. When the carbon and energy source was to be rate-limiting, $5 \mathrm{mM}$ glucose or $3.5 \mathrm{mM}$ maltose was supplied, along with $10 \%(\mathrm{v} / \mathrm{v})$ horse serum. For non-rate-limiting levels of the carbon source, $45 \mathrm{mM}$ glucose and $30 \mathrm{mM}$ maltose and $6.5 \%$ horse serum were added. Undiluted horse serum contained approximately $5 \mathrm{mM}$ glucose. The actual carbohydrate concentration was determined for every batch of medium.

The density of the cultures was determined daily by counting cells in a haemocytometer. Initially the drift of the $\mathrm{pH}$ electrodes was monitored daily by measuring the $\mathrm{pH}$ of a freshly drawn sample with a $\mathrm{pH}$ meter. When drift exceeded 0.02 units, the calibration was corrected. Virtually no drift occurred after an initial $48 \mathrm{~h}$ period and thus $\mathrm{pH}$ was measured only $2-4$ times per week. When culture conditions remained constant for at least five volume changes and the cell density remained unchanged for at least $24 \mathrm{~h}$, the culture was assumed to be in steady state. After measuring the dilution rate and carrying out the sampling programme described below, conditions were changed according to experimental design by varying the dilution rate and/or changing the composition of the medium.

Determination of metabolic parameters. At every steady state, culture fluid was removed and centrifuged at $13000 \mathrm{~g}$ for $18 \mathrm{~s}$. Sedimented cells and cell-free culture fluid were stored at $-20{ }^{\circ} \mathrm{C}$ for the determination of the following: residual glucose and/or maltose concentration in the culture fluid, cell density, protein content and total carbohydrate content of sedimented cells.

Glucose and maltose concentrations in the culture fluid were measured on samples that were drawn and filtered $(0.2 \mu \mathrm{m}$ pore size) within $15 \mathrm{~s}$. Glucose was determined enzymically on duplicate samples according to Bergmeyer (1974). Maltose was assayed as glucose after complete hydrolysis by yeast $\alpha$ glucosidase (Boehringer, cat. no. 105414): $5 \mu \mathrm{l}$ sample and $5 \mu \mathrm{l}$ $\alpha$-glucosidase suspension were incubated in $100 \mu \mathrm{l} 0 \cdot 1 \mathrm{M}$ sodium acetate buffer $\mathrm{pH} 6.6$ for $30 \mathrm{~min}$ at $37^{\circ} \mathrm{C}$. Standards of known 
maltose concentration were used to ascertain the completeness of the hydrolysis and unhydrolysed parallel samples served as blanks. Protein was measured by the Bradford method (Bradford, 1976). Total carbohydrates were measured with the anthrone reagent.

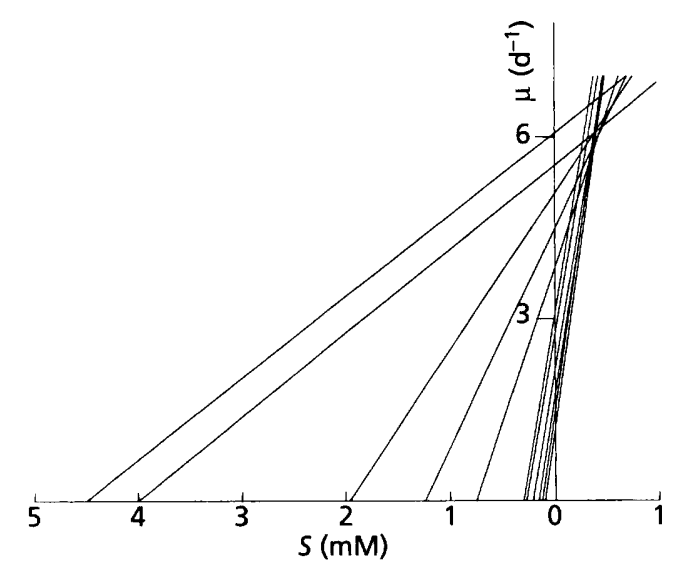

Fig. 1. Direct linear plot (Eisenthal \& Cornish-Bowden, 1974) of the specific growth rate $(\mu)$ of $T$. vaginalis and the corresponding steady-state substrate concentration $(S)$ for cells rate-limited by glucose. The substrate concentration given on the negative $x$ co-ordinate is connected to the growth rate plotted on the $y$ co-ordinate and the crossing points of the extrapolated lines of several data pairs give the values of the $K_{\mathrm{m}}$ on the $x$ co-ordinate and the $\mu_{\max }$ on the $y$ co-ordinate. The maximum growth rate is approximately 6 doubling times $\mathrm{d}^{-1}$ and the apparent $K_{\mathrm{m}}$ for glucose is $0.375 \mathrm{mM}$. The data set for the highest growth rate $\left(D=6.05 \mathrm{~d}^{-1}\right)$ does not obey the same kinetics, as is often found at high $D$, when substrate is no longer rate-limiting.

\section{RESULTS}

\section{Growth on glucose}

The relationship between the external glucose concentration $\left[\mathrm{Glc}_{\text {out }}\right]$ and the growth rate of $T$. vaginalis was determined over a wide range of growth rates (Figs 1 and 2) and found to obey Michaelis-Menten kinetics. The maximum growth rate and the affinity of $T$. vaginalis for glucose were estimated using the direct linear plot (Eisenthal \& Cornish-Bowden, 1974) to be approximately 6 doubling times $\mathrm{d}^{-1}\left(t_{2}=4 \mathrm{~h}\right)$ and $0.375 \mathrm{mM}$, respectively (Fig. 1). The maximum growth rate is equal to the growth rate of batch cultures and at $D$ values exceeding $6.05 \mathrm{~d}^{-1}$ the culture was washed out. The apparent $K_{\mathrm{m}}$ of the intact organism for glucose (the glucose concentration in the culture vessel giving $0.5 \mu_{\text {max }}$ ) differs from the $K_{\mathrm{m}}$ of the transporter (1.6 mM; Ter Kuile \& Müller, 1993) and the $K_{\mathrm{m}}$ of purified glucokinase $(0.035 \mathrm{mM}$; Mertens \& Müller, 1990), indicating shared control over the pathway by both steps. A $K_{\mathrm{m}}$ value for the intact cell that is in between the $K_{\mathrm{m}}$ values of the transporter and the rate-limiting step of the subsequent metabolism is in agreement with the kinetics of facilitated diffusion followed by an enzymatic reaction (Ter Kuile \& Cook, 1994). The glucose concentration in the culture fluid at the highest dilution rate is less than predicted. At growth rates approaching the maximum growth rate $\left(\mu_{\max }\right)$ the rate-limiting substrate is no longer the sole factor controlling the growth rate (Veldkamp, 1976); therefore at such high growth rates Michaelis-Menten kinetics are no longer obeyed. Medium without added carbohydrate was used to ascertain whether glucose was indeed the sole carbon and energy source. The cell density obtained using such medium was $12 \%$ of the density at the same dilution rate in the presence of $5 \mathrm{mM}$ glucose and could be
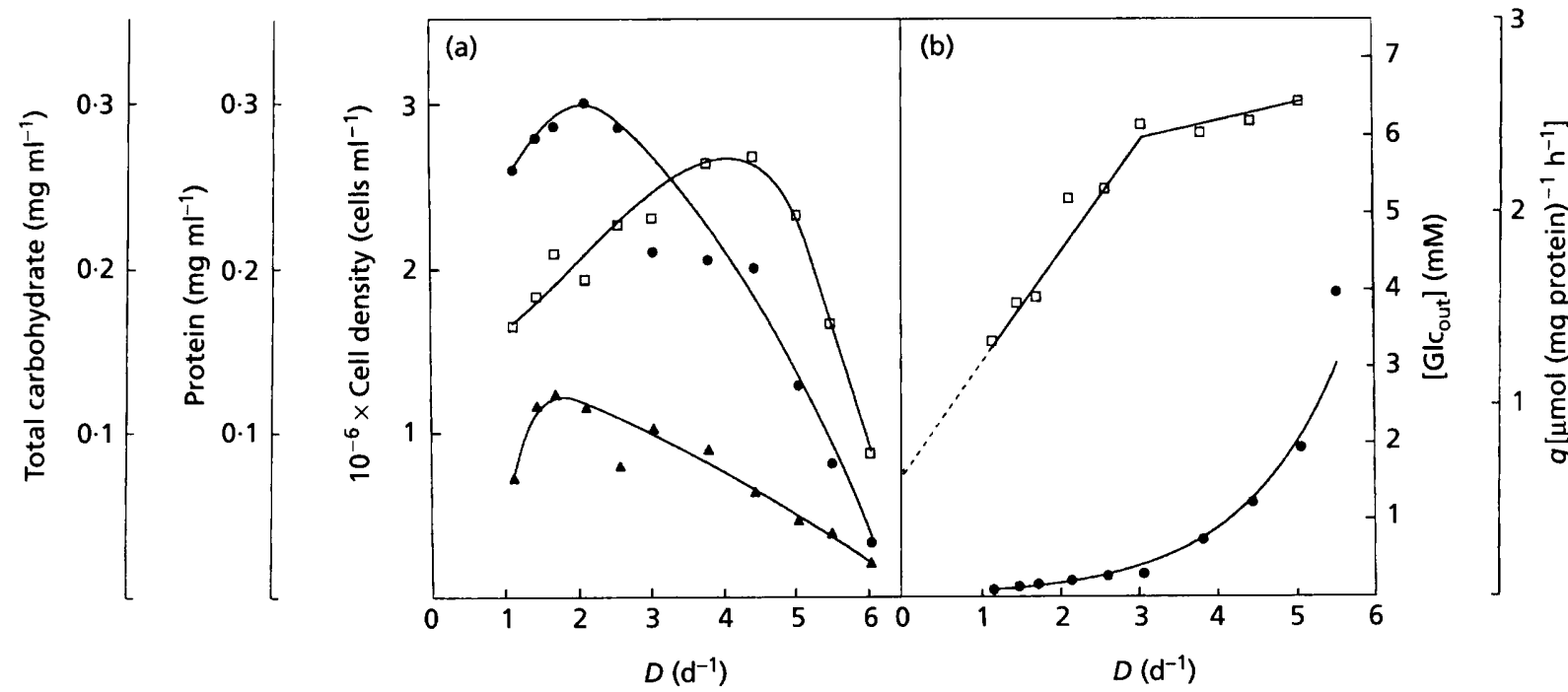

Fig. 2. Cellular parameters as a function of the dilution rate for $T$. vaginalis rate-limited by glucose. (a) Cell density (O); cellular protein content $(\square)$; total cellular carbohydrate $(\boldsymbol{\Delta})$. Note that the protein content per cell is not constant. (b) Steady-state glucose concentration $(0)$; specific glucose consumption, $q(\square)$. 


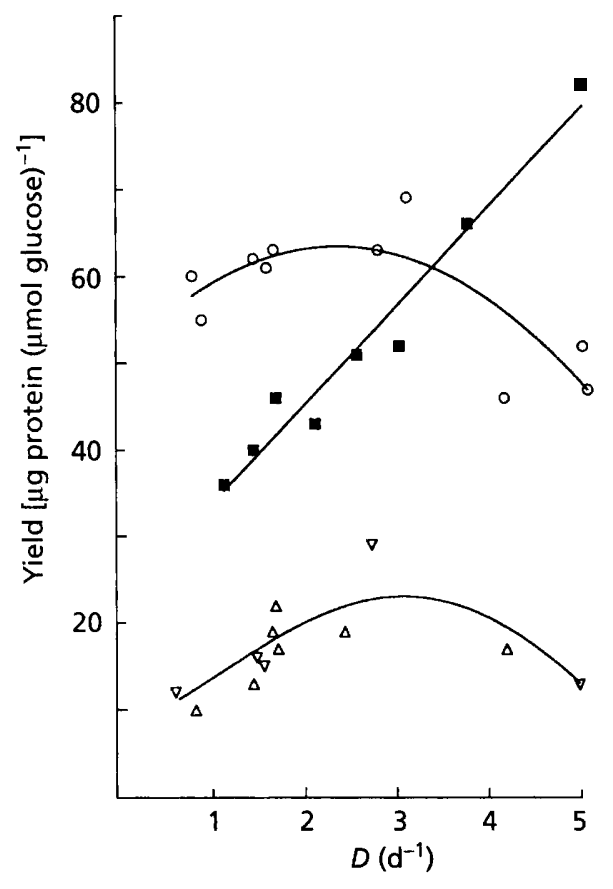

Fig. 3. Comparison of the yields, in $\mathrm{mg}$ protein ( $\mu \mathrm{mol}$ hexose equivalent utilized) ${ }^{-1}$, of $T$. vaginalis cultured under four carbon regimes: glucose or maltose as carbon source, ratelimiting or present in excess. $\mathbf{n}$, Glucose rate-limiting; $O$, maltose rate-limiting; $\triangle$, glucose non-rate-limiting; $\nabla$, maltose non-rate-limiting.

attributed fully to the glucose present in the horse serum $(0.526 \mathrm{mM}$ final concentration).

Maximum cell density and maximum total cellular carbohydrate content of cultures of $T$. vaginalis grown under glucose limitation were reached at a $D$ value of approximately $2 \mathrm{~d}^{-1}$, while cellular protein peaked at a $D$ value of $4 \mathrm{~d}^{-1}$ (Fig. 2a). Thus the protein content varied between 65 and 200 pg protein per cell. Such changes in protein content were not observed under any of the other conditions applied. The yield calculated as $\mathrm{mg}$ protein ( $\mu \mathrm{mol}$ glucose metabolized) ${ }^{-1}$ increased linearly with increasing $D$ (Fig. 3), as is usually observed in eubacteria (Veldkamp, 1976). The yield calculated as cells ( $\mu \mathrm{mol}$ glucose $^{-1}$ gave maximum values between $D$ values of 2 and $4 \mathrm{~d}^{-1}$ (data not shown). The specific substrate consumption, $q\left[\mu \mathrm{mol}(\mathrm{mg} \text { protein })^{-1} \mathrm{~h}^{-1}\right]$, depended linearly on $D$ below and above a $D$ value of $3 \mathrm{~d}^{-1}$, but showed a break-point at that value. In the lower range $q$ increased more rapidly with increasing $D$. The maintenance energy, defined as substrate consumed for all purposes other than growth, can be estimated to be $0.7 \mu \mathrm{mol}$ glucose (mg protein $)^{-1} \mathrm{~h}^{-1}$ by extrapolating $q$ to $D=0$ (Fig. 2b). The maintenance energy accounts for up to $50 \%$ of the total substrate consumption, considerably more than is generally observed in eubacteria and yeasts (2-10\%; Stouthamer, 1977, 1979) and in Leishmania donovani (15-27\%; Ter Kuile \& Opperdoes, 1992b). Above a $D$ value of approximately $3 \mathrm{~d}^{-1}\left(0.5 \mu_{\max }\right), T$. vaginalis changed to a more energy efficient metabolism, as shown by a continued increase in yield accompanied by a slower increase of the specific substrate consumption. At higher $D$ values, up to $40 \%$ less substrate was used than predicted by extrapolation of the first part of the curve (Fig. 2). Such a change to a more energy-saving metabolism was also observed in $L$. donovani, with a breakpoint at $0.5 \mu_{\max }$ as well (Ter Kuile \& Opperdoes, $1992 \mathrm{~b}$ ). Below a $D$ value of $1 \cdot 2 \mathrm{~d}^{-1}$, no stable steady-state could be obtained, indicating that the organisms are unable to cope with severe energy limitation.

Cultures of $T$. vaginalis grown on excess glucose, when another component of the medium becomes rate-limiting, showed a distinctly different behaviour (Fig. 4). First, the protein content of the cells remained constant at approximately $100 \mathrm{pg}$ protein per cell. Second, much higher levels of cellular total carbohydrates were maintained, indicating that more storage materials were made. Third, there was no Michaelis-Menten relationship between $\left[\mathrm{Glc}_{\text {out }}\right]$ and $\mu$ (Fig. 4). Fourth, the dependence of $q$ on $D$ was not linear and the yield was much lower (Fig. 3), indicating a less controlled and more inefficient metabolism. Maximum cell density was obtained below a $D$ value of $2 \mathrm{~d}^{-1}$ and a stable steady-state could still be reached at a $D$ value of $0.8 \mathrm{~d}^{-1}$, because the organisms were not subject to energy depletion.

\section{Growth on maltose}

Cultures grown on rate-limiting concentrations of maltose had the same protein content per cell as those grown on excess glucose (100 pg protein per cell; Fig. 5a). Maximum density was at $D$ values around $2 \mathrm{~d}^{-1}$ and the cellular total sugar content was, surprisingly, a constant but low amount per $\mathrm{ml}$ culture fluid, independent of the cell number. The growth rate depended on the external maltose concentration, [Malt ${ }_{\text {out }}$ ], in a linear manner, suggesting that a diffusion-limited step is the rate-limiting factor. Since maltose is hydrolysed by $T$. vaginalis extracellularly into glucose that is subsequently either taken up through a facilitated diffusion carrier or diffuses back into the medium (Ter Kuile \& Müller, 1994), glucose was measured as well. The concentration of glucose in the culture fluid of maltose-limited cultures was always below $\left[G c_{\text {out }}\right]$ of the corresponding $D$ in glucose limited cultures, but showed a similar dependence on $D$ as observed in glucose-limited cultures. A direct linear plot of [Glc $c_{\text {out }}$ ] against $D$ gave a $\mu_{\max }$ between 5 and $7 \mathrm{~d}^{-1}$ and a $K_{\mathrm{m}}$ between $0 \cdot 110$ and $0.220 \mathrm{mM}$ (data not shown), about half the $K_{\mathrm{m}}$ for glucose of cells growing on glucose. Because the conversion of maltose into glucose occurs outside of the cell, the concentration of glucose close to the transporter determines the growth rate. The lower $\left[\mathrm{Glc}_{\text {out }}\right]$ than observed in glucose-limited cultures would indicate that the organism experiences a higher glucose concentration in the stagnant layer around the cell than is measured in the culture fluid. At low growth rates, the specific substrate consumption in glucose equivalents was lower than in glucose-limited cultures and the estimated maintenance energy was low as well (Fig. 5b). The yield, again per glucose equivalent, was higher than the yield of 


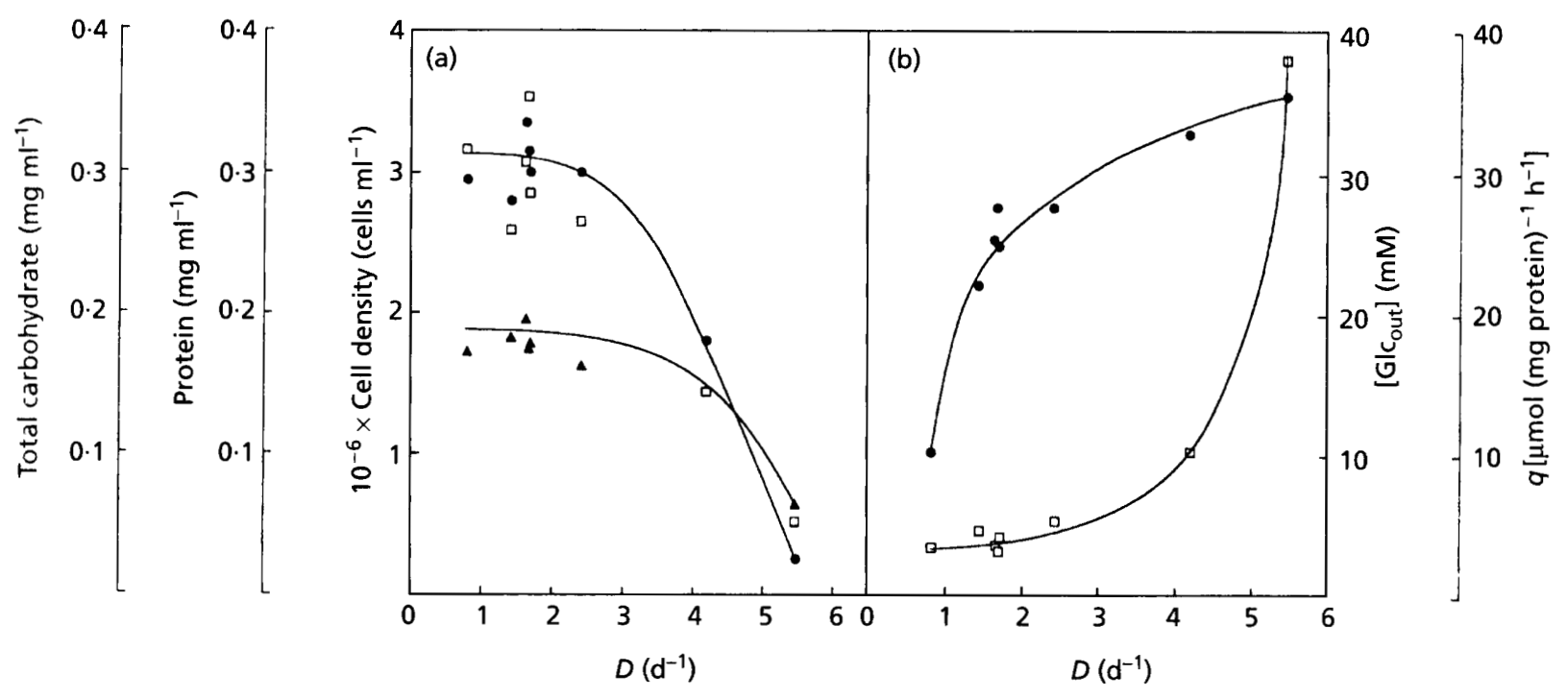

Fig. 4. Cellular parameters for $T$. vaginalis grown on non-rate-limiting glucose concentrations. (a) Cell density (O); cellular protein content $(\square)$; total cellular carbohydrate $(\boldsymbol{\Delta})$. (b) Steady-state glucose concentration (O); specific glucose consumption, $q(\square)$.
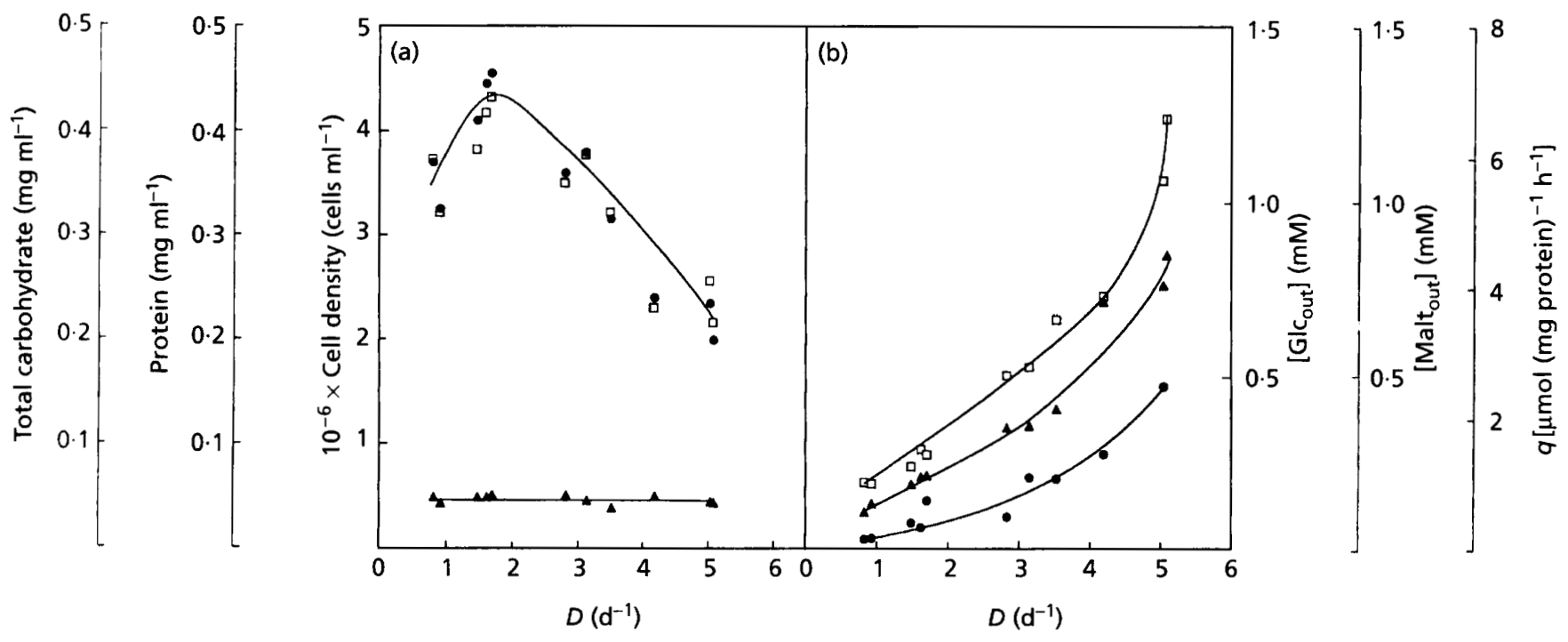

Fig. 5. Cellular parameters for maitose-limited culture of $T$. vaginalis. (a) Cell density (O); cellular protein content ( $\square$ ); total cellular carbohydrate $(\boldsymbol{A})$. (b) Steady-state maltose concentration ( $\square$ ), steady-state glucose concentration (0); specific substrate consumption in glucose equivalents $(\boldsymbol{A})$. Note the linear relationship between the growth rate and the maltose concentration at all but the highest dilution rates.

glucose-limited cultures in the low $D$ range, but at $D$ values exceeding $4 \mathrm{~d}^{-1}$, it dropped significantly (Fig. 3 ).

The protein content and cell density of cultures growing on excess maltose declined linearly with increasing growth rate (Fig. 6a). Again, the total cellular carbohydrate content remained constant per $\mathrm{ml}$ culture fluid. The dependence of the $\left[\mathrm{Malt}_{\text {out }}\right]$ on $D$ was linear (Fig. 6b). The [Glc $\left.\mathrm{Gut}_{\text {out }}\right]$ showed highest levels at the intermediate $D$ values. This pattern might initially seem unexpected, but it can easily be understood by taking into account that maltose is cleaved outside of the cell into glucose. At very low $D$ the maltose concentration, and thus the glucose concentration, was low. At very high dilution rates, the specific substrate consumption is very high and glucose cannot accumulate. At the intermediate growth rates, $q$ is much lower, but the maltose concentrations and the residence time of the culture fluid are much higher, hence glucose can accumulate. The strong increase of $q$ at the highest growth rates indicates, as was found for cultures 


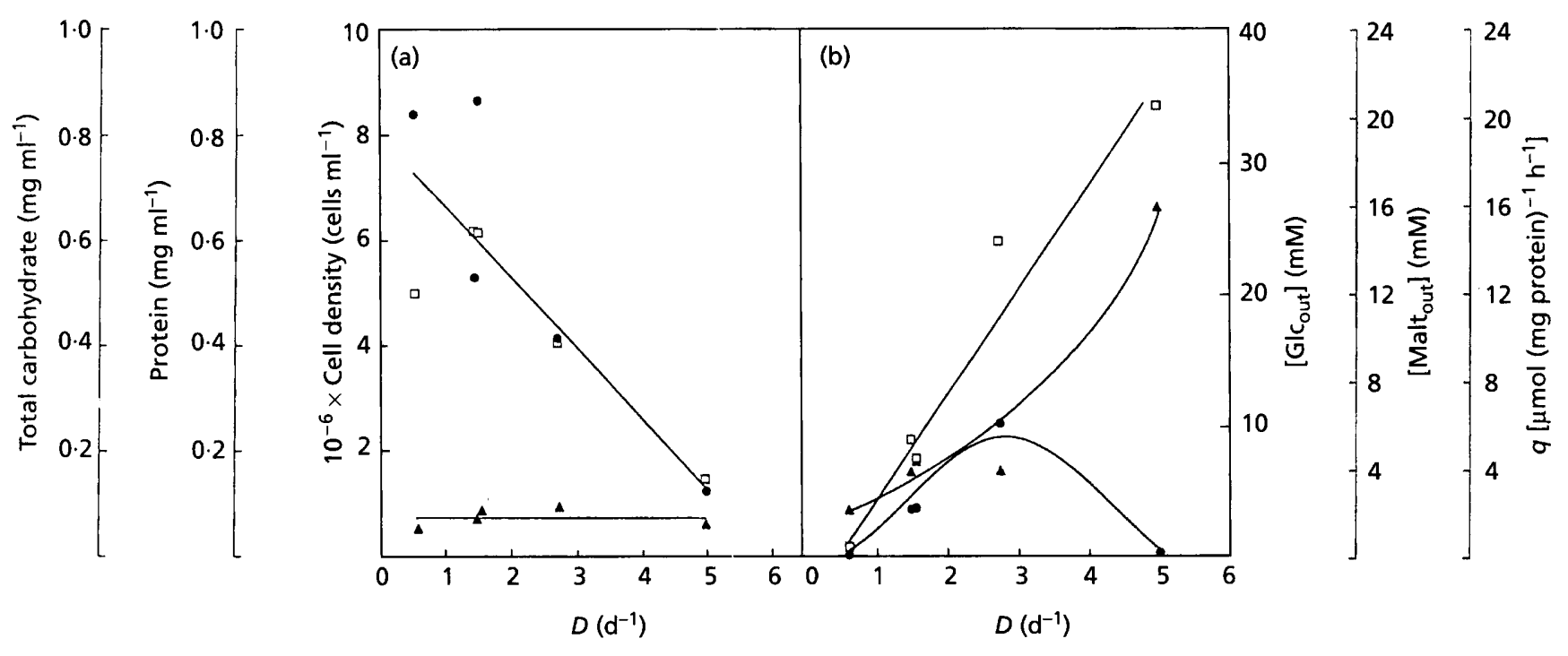

Fig. 6. Cellular parameters for culture grown on excess maltose as carbon and energy source. (a) Cell density (O); cellular protein content $(\square)$; total cellular carbohydrate $(\boldsymbol{\Delta})$. (b) Steady-state maltose concentration ( $\square$ ); steady-state glucose concentration (C); specific substrate consumption in glucose equivalents $(\boldsymbol{\Delta})$.

growing on excess glucose, a wasteful metabolism under these conditions. The yield, calculated per glucose equivalent, was similar to the yield of organisms grown on excess glucose.

\section{DISCUSSION}

The aim of this study was to characterize the overall carbon and energy metabolism of $T$. vaginalis. The very low density of cultures having only the glucose present in the horse serum as carbohydrate source shows that the amino acids of the medium cannot support growth of the laboratory strain used in our study. Hence the glucose or maltose added to the medium were the primary carbon and energy source and the uptake and conversion of other components of the medium does not interfere with the analysis of the carbon and energy metabolism.

\section{Efficiency of the energy metabolism}

Crucial parameters to be determined for the description of carbon physiology are the yield and the maintenance energy. Carbon-limited cultures had higher yields than those growing in the presence of excess carbon and energy source, as is generally observed for a wide variety of micro-organisms (Stouthamer, 1979; Tempest \& Neijssel, 1980). Otherwise, the pattern of the yields obtained by $T$. vaginalis on the different carbon sources differs in many respects from what is generally described for eubacteria and yeasts. Only cultures rate-limited by glucose show the pattern usually observed for other micro-organisms, i.e. linear increase of the yield with increasing growth rates (Veldkamp, 1976; Stouthamer, 1979; Tempest \& Neijssel, 1984). Greater yield of $T$. vaginalis grown on maltose than grown on glucose (per glucose equivalent) has been noted in this study and was observed earlier in batch cultures of $T$. gallinae (Daly, 1970). Batch cultures growing on maltose resemble cultures growing on rate-limiting concentrations of glucose, because the hydrolysis of maltose proceeds at rates that probably keep $\left[\mathrm{Glc}_{\text {out }}\right]$ limiting. Glucose-limited cultures have a 3-10-fold higher yield than those grown on excess glucose. For continuous cultures limited either by glucose or by maltose the explanation that growth on maltose resembles rate-limitation by glucose cannot be valid. The hydrolysis of maltose cannot be used to generate additional energy. Lactobacilli possess a mechanism for phosphorylating maltose without the expenditure of ATP, hydrolysing the maltose-phosphate and releasing up to $1 \mathrm{~mol}$ glucose per mol maltose (Stolz et al., 1993). Such a mechanism may be energy saving, but only to a small extent, and would have resulted in higher glucose concentrations in the culture fluid than observed in this study. The most likely explanation is that the up to fivefold higher formation of storage carbohydrates by cells grown on glucose than by those grown on maltose accounts for the difference in yield.

The optimum yield of $T$. vaginalis growing on maltose or excess glucose around a $D$ value of $3 \mathrm{~d}^{-1}$ could be due to changes of the relative quantities of the end-products so as to more completely oxidize the carbon source at low $D$ than at high $D$, and thus changing the amount of ATP synthesized per molecule of glucose consumed. The switch, also at a $D$ value of $3 \mathrm{~d}^{-1}$, to a more energy-saving metabolism in glucose-limited T. vaginalis, is more likely to be caused by a decrease of the portion of total available energy spent on non-growth purposes. It is tempting to speculate that this change is related to the increase with increasing $D$ of protein per cell, and thus cell size, observed in T. vaginalis growing under glucose limitation, but not under any of the other regimes applied. If this is 
correct, the larger cells would be more energy efficient, at least in the case of $T$. vaginalis.

\section{Habitat and maintenance energy}

The maintenance energy of $T$. vaginalis constitutes up to half its carbohydrate consumption, far more than is usually found in yeasts and eubacteria (Stouthamer, 1977, 1979; Tempest \& Neijssel, 1984) and about double the proportion that Leishmania donovani devotes to nongrowth purposes (Ter Kuile \& Opperdoes, 1992b; Ter Kuile, 1993). The maintenance energy is to a large extent utilized to maintain internal homeostasis (Veldkamp, 1976; Stouthamer, 1977, 1979; Tempest \& Neijssel, 1984). (Organisms adapt to their environment in the least energ $v$-demanding manner that allows the maintenance of all essential functions (Hochachka \& Somero, 1984). The greater the difference between the extracellular and intracellular conditions, and thus the greater the gradients across the plasma membrane, the higher the maintenance energy is likely to be (Tempest \& Neijssel, 1984). The bloodstream form of Trypanosoma brucei does not regulate its internal $\mathrm{pH}$ at $37^{\circ} \mathrm{C}$, the temperature in the mammalian bloodstream, but induces a $\mathrm{pH}$-regulating mechanism at lower temperatures (Ter Kuile et al., 1992). Regulation is not needed in the well-buffered bloodstream, but becomes necessary after transfer to the midgut of the tsetse fly. This may serve as an example of the induction of a regulating mechanism according to necessity. To grow and survive in the vagina Trichomonas vaginalis needs to tolerate an acid $\mathrm{pH}$, which can be as low as $\mathrm{pH} 4$ (Alderete et al., 1986) and the discontinuous supply of nutrients caused by the changing vaginal environment. Like any other organism, $T$. vaginalis needs a $\mathrm{pH}$-regulating mechanism to maintain a neutral internal $\mathrm{pH}$ at low external $\mathrm{pH}$, at the expense of maintenance energy. The existence of such a mechanism has not been investigated in $T$. vaginalis, but would be consistent with the high maintenance energy found in this study.

Both the rate and the composition of the nutrient supply can vary. Fluctuations in the carbon supply can be countered by mobilizing the carbohydrate reserves that $T$. vaginalis accumulates when growth is not rate-limited by the carbon source. Growing at high rates on excess glucose, T. vaginalis contains as much carbohydrate as protein, but the total cellular carbohydrate content of maltose-limited cultures can be as low as $10 \%$ of the protein content. The outcome of this study and the data on very slow growth (Lehker \& Alderete, 1990) indicate that $T$. vaginalis can survive non-growth or very slow growth as long as it is not starved of carbon and energy. The high maintenance energy may be the major reason that carbon-limited cells lysed when grown at growth rates corresponding to doubling times of more than $20 \mathrm{~h}$. Similarly, a better viability is generally found for nitrogenlimited than for carbon-limited cultures of eubacteria growing at low rates (Veldkamp, 1976). This in turn suggests optimal adaptation to conditions where nutrients other than the carbon and energy source are limiting growth.
The carbohydrate metabolism of the insect stages of two other species of parasitic protists, Tryp. brucei and $L$. donovani, was studied in chemostats and it was suggested that their metabolic strategies could be linked to the environmental challenges encountered in their respective habitats (Ter Kuile \& Opperdoes, 1992b). The insect stage of Tryp. brucei forms no storage carbohydrates and adapts its glucose metabolism in a manner opposite to $T$. vaginalis, i.e. by increasing both the transport and the metabolic capacity when more glucose is available, thus amplifying the fluctuations (Ter Kuile \& Opperdoes, 1992a). In contrast, $L$. donovani barely adapts its glucose metabolism (Ter Kuile \& Opperdoes, 1993; Ter Kuile, 1993 ) and exerts a strict control over its internal conditions (Zilberstein, 1991). This control is exercised at the expense of maintenance energy, which is up to a quarter of the total energy consumption. The metabolism of $T$. vaginalis has as a primary feature a very high maintenance energy, probably for regulation of its internal conditions. On the other hand, an ectoenzyme is used for hydrolysis of maltose (Ter Kuile \& Müller, 1994), rather than a separate transporter as found in prokaryotes (Schwartz, 1987) and yeasts (Benito \& Lagunas, 1992), allowing much less tight control over the utilization of the glucose formed. The high maintenance energy and the use of an ectoenzyme for maltose hydrolysis may be considered to be not the most efficient use of the carbohydrate source, suggesting that $T$. vaginalis focuses on survival within the host rather than optimal use of the carbon and energy resources.

\section{ACKNOWLEDGEMENTS}

This study was supported by NIH grants AI 11942 and RR 07065. The author thanks Dr M. Müller for stimulating discussions and important criticisms on earlier versions of this manuscript. The author was the recipient of a fellowship from the Norman and Rosita Winston Foundation. However, the statements made and the views expressed are solely the responsibility of the author.

\section{REFERENCES}

Alderete, J. F., Garza, G., Smith, J. \& Spence, M. (1986). Trichomonas vaginalis: electrophoretic analysis and heterogeneity among isolates due to high molecular weight trichomonad proteins. Exp Parasitol 61, 244-251.

Benito, B. \& Lagunas, R. (1992). The low-affinity component of Saccharomyces cerevisiae maltose transport is an artifact. J Bacteriol 174 , 3065-3069.

Bergmeyer, H. U. (1974). Enzymes as biochemical reagents: hexokinase. In Methods of Enzymatic Analysis, p. 473. Edited by H. U. Bergmeyer. New York: Academic Press.

Bradford, M. M. (1976). A rapid and sensitive method for the quantitation of microgram quantities of protein utilizing the principle of protein-dye binding. Anal Biochem 72, 248-254.

Daly, J. J. (1970). The maltose metabolism of Trichomonas gallinae (Rivolta, 1878): I. Growth studies. J Parasitol 56, 883-888.

Diamond, L. S. (1957). The establishment of various trichomonads of animals and man in axenic cultures. $J$ Parasitol 43, 488-490.

Eisenthal, R. \& Cornish-Bowden, A. (1974). The direct linear plot. A new graphical procedure for estimating enzyme kinetic parameters. Biochem J 139, 715-720. 
Fouts, A. C. \& Kraus, S. J. (1980). Trichomonas vaginalis: reevaluation of its clinical presentation and laboratory diagnosis. J Infect Dis 141, $137-143$.

Hochachka, P. W. \& Somero, G. N. (1984). Biochemical Adaptation. Princeton, NJ: Princeton University Press.

Lehker, M. W. \& Alderete, J. F. (1990). Properties of Trichomonas raginalis grown under chemostat controlled growth conditions. Genitourin Med 66, 193-199.

Lloyd, D. \& Paget, T. A. (1991). The effects of environmental factors on the metabolism of Giardia and Trichomonas. In Biochemica! Protozoology 1990, pp. 92-101. Edited by G. H. Coombs \& M. J North. London: Taylor \& Francis.

Mack, S. R. \& Müller, M. (1980). End products of carbohydratc metabolism in Trichomonas vaginalis. Comp Biochem Pbysiol 67B, 213- 216.

Mertens, E. \& Müller, M. (1990). Glucokinase and fructokinase of Trichomonas vaginalis and Tritrichomonas foetus. J Protozool 37, 384. 388.

Müller, M. (1988). Energy metabolism of protozoa without mitochondria. Annu Rev Microbiol 42, 465-488.

Müller, M. (1991). Energy metabolism of anaerobic parasitic protists. In Biochemical Protozoology, pp. 80-91. Edited by G. H. Coombs \& M. J. North. London: Taylor \& Francis.

Müller, M. (1993). The hydrogenosome. J Gen Microbiol 139, 2879.2889.

Read, C. P. (1957). Comparative studies on the physiology of trichomonad protozoa. J Parasitol 43, 385-394.

Schwartz, M. (1987). The maltose regulon. In Escherichia coli and Salmonella typhimurium Cellular and Molecular Biology, pp. 1482-1502. Edited by F. C. Neidhardt and others. Washington, DC: American Society for Microbiology.

Simonetti, G., Simonetti, N. \& D'Auria, F. D. (1989). Glycogen medium, antitrichomonal drug activity in vaginal liquids. Drugs Expt/ Clin Res 15, 545-547.

Stolz, P., Bocker, G., Vogel, R. F. \& Hammes, W. P. (1993). Utilisation of maltose and glucose by lactobacilli isolated from sourdough. FEMS Microbiol Lett 109, 237-242.

Stouthamer, A. H. (1977). Energetic aspects of the growth of micro-organisms. Symp Soc Gen Microbiol 27, 285-315.

Stouthamer, A. H. (1979). The search for correlation between theoretical and experimental growth rates. Int Rev Biochem 21,1-47.

Tempest, D. W. \& Neijssel, O. M. (1980). Growth yield values in relation to respiration. In Diversity of Bacterial Respiration Systems I, pp. 1-31. Edited by C. Knowles. Boca Raton, Florida: CRC Press.

Tempest, D. W. \& Neijssel, O. M. (1984). The status of $Y_{\text {ATP }}$ and maintenance energy as biologically interpretable phenomena. Annu Rev Microbiol 38, 459-486.

Ter Kuile, B. H. (1994). Adaptation of the carbon metabolism of Trichomonas vaginalis to the nature and availability of the carbon source. Microbiology 140, 2503-2510.

Ter Kuile, B. H. \& Cook, M. (1994). The kinetics of facilitated diffusion followed by enzymatic conversion of the substrate. Biocbim Biopbys Acta (in press).

Ter Kuile, B. H. \& Müller, M. (1993). Interaction between facilitated diffusion of glucose across the plasma membrane and its metabolism in Trichomonas vaginalis. FEMS Microbiol Lett 110, 27-32.

Ter Kuile, B. H. \& Müller, M. (1994). Maltose utilization by extracellular hydrolysis followed by glucose transport in the amitochondriate eukaryote, Tricbomonas vaginalis. Parasitology (in press).

Ter Kuile, B. H. \& Opperdoes, F. R. (1991). Chemostat cultures of Leishmania donovani promastigotes and Trypanosoma brucei procyclic trypomastigotes. Mol Biochem Parasitol 45, 171-174.

Ter Kuile, B. H. \& Opperdoes, F. R. (1992a). Mutual adjustment of glucose uptake and metabolism in Trypanosoma brucei grown in the chemostat. J Bacteriol 174, 1273-1279.

Ter Kuile, B. H. \& Opperdoes, F. R. (1992b). Comparative physiology of two protozoan parasites, Leishmania donovani and Trypanosoma brucei, grown in chemostats. J Bacteriol 174, 2929-2934.

Ter Kuile, B. H. \& Opperdoes, F. R. (1993). Uptake and turnover of glucose in Leishmania donovani. Mol Biochem Parasitol 60, 313-322.

Ter Kuile, B. H., Wiemer, E. A. C., Michels, P. A. M. \& Opperdoes, F. R. (1992). 'The electrochemical proton gradient in the bloodstream form of Trypanosoma bruce $i$ is dependent on the temperature. Mol Biochem Parasitol 55, 21-28.

Ter Kuile, B. H. (1993). Glucose and proline transport in kineto. plastids. Parasitol Today 9, 206-210.

Veldkamp, H. (1976). Continuous Culture in Microbial Pbysiology and Ecology. Durham, UK: Meadowfield Press.

Zilberstein, D. (1991). Adaptation of Leishmania species to an acidic environment. In Biochemical Protozoology, pp. 349-358. Edited by G. H. Coombs \& M. J. North. London: Taylor \& Francis.

Received 25 February 1994; revised 3 May 1994; accepted 11 May 1994. 